\title{
Formalising Research Methods for Graduate Programs in Computer Science
}

\author{
Meriel Huggard ${ }^{1}$ and Ciarán Mc Goldrick ${ }^{2}$
}

\begin{abstract}
Traditional M.Sc. and Ph.D. programs are being supplemented by "fourth-level", integrated Ph.D. programs which seek to formalise the transition from undergraduate to postgraduate study. As well as undertaking formal modules, graduate students on these programs are expected to quickly learn how to plan, manage and conduct research. They should also know how to present the outcomes of their research in peerreviewed publications. Moreover, they must be able to reflect critically on existing research as well as on their own findings. In the development of one such integrated Ph.D. program it was found that there is little agreement on the constituent elements of a module on Computing Research Methods or on the pedagogical principles to be employed in the preparation and delivery of such a module. This paper reports on the design, experience and assessment of a graduate level module on research methods in computer science, documenting how it was planned and realised, reporting on the staff and student experiences, and providing both objective and subjective assessments of the module and its outcomes.
\end{abstract}

Index Terms - Research Methods, Computer Science, Graduate Program

\section{INTRODUCTION}

As part of Ireland's drive to maintain its current competitiveness in the global technology marketplace, the Government has identified a strategic need for the provision of "fourth-level", integrated Ph.D. programs. It is essential that graduate students on these programs be capable of engaging in critical appraisal and logical, reasoned analysis of the state of the art in their chosen discipline. These students must also be able to clearly, concisely and accurately articulate their research goals and intended outcomes for the purpose of dissemination in the professional literature. It is currently unclear as to how the development of these research skills will be achieved on the integrated Ph.D. programs in Computer Science. Moreover, there is little agreement on the constituent elements of a module on Computing Research Methods [1,2] or on the pedagogy to be employed in the preparation and delivery of such a module $[3,4,5]$.
Historically, research methods have been taught through the apprenticeship model where the graduate student learns the necessary discipline specific research skills from their advisor. This process is labour intensive and requires the advisor to spend many hours working on a one-to-one basis with the student. Furthermore, the specialised nature of research at the graduate level means that the graduate student may not acquire research skills that allow them to move beyond those required in their specialised field.

In recent years, many self-help style guide books have been written to provide graduate students with an insight into research methods and to assist them in the preparation of a $\mathrm{Ph} . \mathrm{D}$. thesis. These are often very general in nature and typically focus on one aspect of the research cycle e.g. how to write a research paper or how to carry out postgraduate research $[6,7,8]$. They do not provide a discipline-specific introduction to research methods for graduate students in computer science.

This paper reports on the design, experience and assessment of a graduate level module on research methods in computer science. Our experiences and findings over the past five years are now being used to refine the module for our integrated Ph.D. programs. Peer and collaborative learning concepts underpin the module design philosophy, as do key elements of the traditional apprentice model of research training. The module design fosters the development of student awareness of both the breath and depth of research methodologies available whilst engendering active engagement and participation with the computer science research community.

\section{COURSE STRucture}

The Research Methods module described herein is a core element of the postgraduate taught M.Sc. in Computer Science (Networks and Distributed Systems) at Trinity College Dublin. This M.Sc. program is full-time and runs over a oneyear period commencing in October each year. Assessment comprises a combination of assigned coursework, written examination and a dissertation. From October to March, students take formal modules over two nine-week semesters. In parallel with this taught element of the M.Sc. program, students commence work on a dissertation under the supervision of a faculty member. Once the formal modules and written examinations have been completed in March, students work full time on their dissertation project which is

\footnotetext{
${ }^{1}$ Meriel Huggard, Department of Computer Science, Trinity College, Dublin 2, Ireland; Meriel.Huggard@tcd.ie

${ }^{2}$ Ciarán Mc Goldrick, Department of Computer Science, Trinity College, Dublin 2, Ireland; Ciaran.McGoldrick@cs.tcd.ie
} 


\section{Session S4G}

submitted that September. The Research Methods module is designed so that students complete one iteration of the research cycle prior to the commencement of full time work on their dissertation projects.

Class size has varied from 15 to 20 students in each of the five years that this module has been delivered. The student body on this course is diverse in nature: over half the class are international students and many of these do not have English as a first language.

Students on this course are provided with a laptop and instructors are encouraged to use these to enhance the learning environment where possible.

\section{Module Design Philosophy}

The research methods module aims to equip postgraduate students with the necessary skills to carry out independent research, thus reducing the supervisory input required from a faculty member or advisor. Hence students need to become familiar with the apprentice model of studentship - learning to work closely with and act on the advice of an academic mentor. As part of the module the students meet regularly with two mentors, the module instructor and a final year Ph.D. student who acts as a teaching assistant (TA). These mentors provide appropriate research advice, feedback and encouragement to the students and ensure that all students participate fully throughout the module. The Ph.D. student is asked to provide the students with similar peer supports to those that would be offered to them in a research laboratory environment. The TA is instructed to act independently of the module instructor during any contact sessions with the students.

The module also incorporates elements of peer and collaborative learning to help students develop an understanding of the research process. The key stages are estabilished as:

- Initial planning

- Identifying the state of the art in the field of interest by means of a literature survey

- Articulation of Research Questions and Project Goals

- Project Planning

- Project Implementation

- Project Evaluation

- Documentation of Findings

- Peer Feedback

- Refinement

- Resubmission of a Research Article

Reciprocal peer learning involves individuals learning from, and with, each other. While it can be as informal as a request to a colleague for information on how to use a computer application, it is often used by students as an integral part of their formal academic learning [9]. In this module students are encouraged to discuss the material they are learning, the learning style they are adopting and any problems they are encountering with their fellow students outside of the classroom setting. The techniques are also used by the graduate students when working on a collaborative project. There are two typical peer learning interactions [10]:

- transfer-of-knowledge sequences, where one student teaches the other something

- Collaborative sequences, where the students work together.

Boud [11] argues strongly in favour of making formalized peer learning an explicit part of all higher education courses. The module described herein fosters peer learning as a necessary and important part of the research process. Students are encouraged to treat the postgraduate teaching assistant as a peer who is there to help them with their research work.

\section{Module Structure}

The module runs over two nine-week semesters, with two timetabled contact hours per week. The class also have access to any necessary laboratory infrastructure for at least six hours per week. Prior to the commencement of the module, students are given a one-hour introductory class where they are introduced to the module design and philosophy. During this session a simple didactic contract is established between the students and the instructors. In particular, the aims of the module are identified and the assessment criteria discussed. At this introductory session five possible research projects are presented. Each student is then asked to submit an ordered list of projects they would like to work on. These lists are used to assign the students to small project groups. Due to the diversity in the academic backgrounds of the student cohort, it has been found that it is almost always possible to assign students to a group working on their first or second preference project. It is an administrative practice to make sure that no group consists only of students who have English as a second language as a native English speaker provides invaluable peer feedback to the group while they are documenting the group's findings.

In order to carry out the project the students will have to search for resources, create a database of research materials, reference other work, plan and implement a project, analyse the results and document the research findings. In order to encourage the development of good time management and project planning skills, five milestones are used:

- $\quad$ Project plan submitted

- Implementation Phase Completed

- Data Gathering and Analysis Completed

- Draft Article Submitted for Peer Review

- $\quad$ Final Article Submitted

Each two hour class begins with a brief 20 minute overview of the relevant research skills needed for the current phase of the project. They are also reminded of the current deliverable deadline and what they should hope to achieve over the following week. During the remaining class time each group spends 20 minutes meeting with the instructor, 20 minutes meeting the TA and 1 hour working together as a group. 
Session S4G

Initially, students are required to perform a literature review. Not only must they be shown how to locate resources, they must also learn how to quickly assess the relevance of any research articles they find. The reference facilities available through the University library (e.g. the IEEE Xplore Database or the ACM Digital Library) are used as the starting point for this activity.

During the initial discussion sessions, each group is pointed towards one relevant research article and one prominent research group that carry out work in their chosen research field. Students then use this material to formulate a research plan. The instructor and the TA use the discussion session to guide the students towards a set of realistic, achievable research goals based on the research questions they have determined for their project. The students are asked to specify any equipment they may require in order to carry out the implementation phase of the project (e.g. a GPS receiver). As a fundamental part of the planning process, students are also required to demonstrate a familiarity with the common theoretical and experimental methods habitually used in their chosen field of enquiry.

The students submit their research plan at the end of the fourth week of the module. The reporting format used is identical to that the students will use for their individual M.Sc. dissertation projects.

Once the research plans have been submitted, the students are provided with written feedback and, if necessary, are asked to reconsider their project objectives in light of the available time constraints. It has been found that written feedback encourages students to address all of the issues that are raised in relation to their research plans

In the second phase of the project students continue with their literature review, but now shift their focus to matters relating to experimental design. The presentation section at the start of each class is used to showcase a variety of computer science research methodologies and encourage their effective use. Students are encouraged to reflect more critically on relevant research articles and to question the appropriateness of the methodology used therein for collecting and analysing data. In tandem with this, students complete the set-up of the experimental design proposed in their research plan. This ensures that, by the end of the first semester, the students have a working experimental test-bed that can be used to gather the data required to allow them address their research questions. At this point the students are required to present their research questions and experimental design to a Faculty member. This Faculty member is asked to treat each group as though they were a graduate student under their supervision and to provide them with appropriate feedback and advice.

In the second semester the focus of the module shifts to the gathering and analysis of experimental data. Significant time is devoted to this phase of the project as it has been found that students are prone to underestimate the importance of this aspect of the research cycle. The presentations at the start of each session now focus on statistical methods and data analysis techniques. Students are asked to assess the significance of the data presented in the context of the research question addressed in key articles considered as part of their literature review. During the discussion sessions the students are required to articulate the inductive and/or deductive reasoning they intend to use in relation to the data they have gathered. Often students collect vast amounts of data and are unsure how to analyse it. The instructor and TA use the group's research objectives to guide them towards appropriate approaches to this problem.

Once all the data has been gathered and analysed the students are in a position to write their research articles. They use the standard IEEE template for Transactions and Journals and are expected to produce an article of between 10 and 15 pages in length. All group members are required to write and contribute to sections of the paper. At this stage, they are also asked to identify relevant calls for publications and required to opine as to whether their work might be suitable for submission. Most students are keen to publish their work and this provides them with an incentive to produce a high quality manuscript. Students are expected to submit a draft manuscript three weeks before the end of the semester. Two or three faculty members then provide peer-review feedback and this is returned to the students in the second last week of term. The students use this process to guide their refinements prior to the final submission deadline.

The timetable for these research activities over the eighteen weeks of the module is given in Table I.

TABLE I

MODULE STRUCTURE

\begin{tabular}{|c|c|c|}
\hline Week & Activity & Deliverable \\
\hline 1 & Overview, Presentation of Research Topics & \\
\hline 2 & Literature and Resource research & \\
\hline 3 & Collation of Research materials & \\
\hline 4 & Project Planning & $\begin{array}{l}\text { Project Plan } \\
\text { Completed }\end{array}$ \\
\hline 5 & Further Literature and Resource Research & \\
\hline 6 & Experimental/Implementation Design & \\
\hline 7 & Experimental set-up/Implementation & \\
\hline 8 & Experimental set-up/Implementation & \\
\hline 9 & Full Implementation Completed & Implementation Completed \\
\hline 10,11 & Data Gathering and Analysis & \\
\hline 12 & Data Gathering and Analysis & Data Analysis Completed \\
\hline 13 & Write Article to document findings & \\
\hline 14 & Write Article to document findings & \\
\hline 15 & Draft Article Submitted & Draft Submission \\
\hline 16 & Discussion on Peer Review Feedback & \\
\hline 17 & Revision and Refinement of Article & \\
\hline 18 & Final Article Submission & Paper Submission \\
\hline
\end{tabular}

October 10 - 13, 2007, Milwaukee, WI

\section{1-4244-1084-3/07/\$25.00 @2007 IEEE}

\section{$37^{\text {th }}$ ASEE/IEEE Frontiers in Education Conference S4G-18}


While not formally part of the module, students are offered the opportunity to give a departmental seminar on their research findings once their course examinations have been completed. Where appropriate, they also submit their work to an appropriate forum within the computer science research community of practice (an example of an article written by students on this module and accepted for publication is [12]).

\section{ASSESSMENT}

As the aim of the module is to guide the students as they develop basic research skills, through a combination of both the apprentice model and peer and collaborative learning, traditional grading and assessment methodologies proved inappropriate. Rather, as the students' objective is to produce a research article for publication and this forms the vehicle for their assessment. The grading criteria used were:

- Identify and articulate an appropriate research question $(10 \%)$

- Motivate the research through appropriate citations from the literature (15\%)

- Fully describe an experimental design suitable for addressing the chosen research questions. (15\%)

- Present results in a clear and appropriate manner (15\%)

- Analyze results obtained and anchor in the literature $(15 \%)$

- Draw appropriate conclusions (10\%)

- Provide a correctly formatted Reference section (10\%)

- Conform fully to the IEEE Formatting Instructions (10\%)

\section{STUdent Evaluation}

When assessing the quality of student learning it is essential to consider the information gathered from individual students as well as the global statistical data gathered from the class. The module described herein relates to a non-traditional learning environment and so the evaluation carried out focused on the quality of the learning and the student engagement with the module. This module has been presented consecutively for the past five years and the evaluation data presented below is a summary of that collected over this period.

Independent module surveys were carried out each year by the M.Sc. program Course Director. These include twenty closed response questions where students must indicate the extent of their agreement/disagreement with a number of statements regarding the module. Students are also asked to list two positive and two negative aspects of anything to do with the module.

This questionnaire showed that over the past 5 years, $89 \%$ of students agreed that they benefited from taking this module, while $83 \%$ agreed that the module objectives were met. Common positive comments related to the relevance of the module to the students dissertation work (62\%), to the helpful feedback received (43\%) and to the fact that the module had only one submission deadline (37\%). On the negative aspects of the module, students commented on the fact that the submission deadline coincided with many others at the end of the last semester $(56 \%)$, on the heavy workload the module placed on them $(23 \%)$ and on the heavy workload placed on the only native English speakers in some groups (12\%)

The instructor also carried out a survey in the 2005/6 academic year to assess how student's viewed the relationship between the module objectives, learning outcomes and learning environment. $87 \%$ of students agreed that they would be more confident about carrying out independent research work after taking this module, while $83 \%$ agreed that they had a better understanding of the role of an advisor when carrying out research work. All students $(100 \%)$ stated that they had engaged fully with the module - this may be attributed to the fact that they were so closely supervised by the instructor and the TA.

The results of the separate evaluations given above clearly indicate that the students felt that the module was of direct benefit to them, particularly as a preparation for the substantial dissertation work to be carried out as part of their M.Sc. All students felt confident that they would be able to independently plan and carry out research work.

\section{STAFF EXPERIENCE}

This module bridges the gap between undergraduate study and postgraduate research work and the instructor's experience of the learning environment reflected this: part of each class session was used for the formal presentation of research methodologies, while the remainder of the time was spent in discussion with the students. The regular, close contact between the instructor and each group means that any student misconceptions and misunderstandings were quickly identified and addressed. It also allowed the instructor to carefully monitor the workings of each group to ensure that all students contributed equally to the research process. This was particularly important in the initial weeks of the module where students who do not have English as a first language were unintentionally excluded by their peers.

The TAs associated with this module over the past five years all enjoyed the experience and felt they benefited greatly from it. Four of the five TAs felt their own research skills were enhanced as a direct result of their association with this module. Indeed, two of the TAs remarked that they would like to have undertaken such a module at the start of their postgraduate studies.

\section{CONCLUSION}

Research requires the use of higher order learning skills such as organising, discarding, discussing, negotiating, interpreting, refinement and problem-solving. The module described herein fosters these skills in the development of graduate students' research ability in the field of Computer Science. The learning environment described uses elements of peer and collaborative learning alongside the apprentice model to provide students with a unique hands-on research experience that formalises the transition from undergraduate to postgraduate study

October 10 - 13, 2007, Milwaukee, WI 


\section{REFERENCES}

[1] SIGCSE-CSRM. ACM SITCSE Committee on Teaching Comptuer Science Research Methods,

http://222.sigcse.org/topics/committees.shtml

[2] Holz, H.J., Applin, A., Haberman, B., Joyce, D., Purchase, H., and Reed, C., "Research Methods in Computing: What are they, and how should we teach them?", ACM SIGCSE Bull., 38, No.4, 2006, pp 96-114

[3] Whitten, I., and Bell, T., "Getting Research students started: a tale of two courses", in Proc. ACM SIGCSE 1993, Indianapolis, IN., March 1993, pp165-269.

[4] Shaffer, C. A., "Experiences teaching a graduate research methods course", ACM SIGCSE Bull., 38, No.2,2006, pp 97-101

[5] Ward, Karen, "The Fifty-Four Day Thesis Proposal: First experiences with a Research Course", J. Comp. Sci. College, 20, 2, 2004, pp 94-109

[6] Greenfield, Tony, "Research Methods for Postgraduates", Oxford University Press, 2002

[7] Phillips, Estelle, and Pugh, Derek, How to Get a PhD, Open University Press, 2005

[8] Zobel, Justin, Writing for Computer Science, $2^{\text {nd }}$ edition, Springer, 2004

[9] Haller, C. R., Gallagher, V.J., Weldon, T.L., Felder, R.M., 'Dynamics of Peer Education in Cooperative Learning Workgroups', J. Engr. Educd., Vol 89, No. 3, 2000, pp. 285-293.

[10] Miskimins, J., 'Peer Learning: Observation of the Cluster Effect in Multidisciplinary Team Settings', in Proc. ASEE Annual Conference \& Exposition, 2003.

[11] Boud, D., Cohen, R., Samson, J., 'Peer Learning in Higher Education', Kogan Page, London, 2001

[12] Cahill, E., Matic, G., Keane, J., and Commins, M., "Bluetooth and 802.11: co-existence or conflict?", Proc $15^{\text {th }}$ International Conference on Computer Communication, 2002, pp26-35. 